\title{
Homozygous Familial Hypercholesterolemia with Generalized Arterial Disease
}

\author{
J.P. Selvan ${ }^{\text {a }} \quad$ B. Uthaman ${ }^{\text {b }} \quad$ L. Abushaban ${ }^{\text {c }} \quad$ R. Jebaraj ${ }^{\text {a }}$ \\ ${ }^{a}$ Department of Cardiology, Chest Diseases Hospital, and Departments of ${ }^{b}$ Medicine and ${ }^{c}$ Paediatrics, \\ Faculty of Medicine, Kuwait University, Kuwait
}

\section{Key Words}

Homozygous familial hypercholesterolemia • Low-density

lipoprotein apheresis

\begin{abstract}
Objective: This report describes the clinical features and management of an 11-year-old boy with end-stage homozygous familial hypercholesterolemia (hoFH) and generalized arterial disease. Clinical Presentation and Intervention: The patient presented with recurrent anginal episodes. On examination, he was found to have multiple planar and tendinous xanthomas, an (LDL) cholesterol level of $24.6 \mathrm{mmol} / \mathrm{l}$ and family history of hypercholesterolemia. Resting electrocardiogram showed ST depression in the anterior and inferior leads. Coronary angiogram outlined $70 \%$ stenosis of the left main coronary, ostial stenosis of the right coronary artery and extensive atherosclerotic disease of the aorta and all its major branches. The lipid profile was grossly abnormal, but the other biochemical and hematological parameters were normal. The patient was managed with metoprolol $12.5 \mathrm{mg}$ twice daily, nitroglycerin infusion, antithrombotics (aspirin $75 \mathrm{mg}$ once daily and heparin infusion 150 units per hour), cholesterol-lowering drugs (simvastatin $10 \mathrm{mg}$ once a day, cholestyramine $4 \mathrm{~g}$ twice a day) and analgesics. Conclusion: This case report emphasizes the need to diagnose ear-
\end{abstract}

ly familial hypercholesterolemia in families with heart disease and the need to test the partners of affected persons so that the risk of conceiving children with hoFH can be counseled.

Copyright $\odot 2007$ S. Karger AG, Basel

\section{Introduction}

Familial hypercholesterolemia is a common autosomally inherited dominant disease afflicting between 1 in 200 and 1 in 500 individuals. It arises from a defect in the low-density lipoprotein (LDL) receptor gene, which causes abnormalities or absence of the LDL receptor and impaired clearance of the circulating LDL $[1,2]$. This type of functional receptor defect affects the extent of elevation of the levels of LDL and the risk and rate of development of atherosclerosis. The heterozygous form, which is more common, leads to hypercholesterolemia and premature heart disease but is more amenable to treatment. Rarely, perhaps once in a million, a patient may be homozygous for familial hypercholesterolemia with extreme elevations of LDL and aggressive development of atherosclerosis. The severity of the disease depends on the functionality of the two inherited abnormal alleles [2]. In this report we describe the clinical features

\section{KARGER \\ Fax +41613061234 \\ E-Mail karger@karger.ch}

www.karger.com
(C) 2007 S. Karger AG, Basel

1011-7571/07/0161-0075\$23.50/0

Accessible online at:

www.karger.com/mpp
Dr. John P. Selvan

Department of Cardiology, Chest Diseases Hospital

PO Box 4082

Safat 13041 (Kuwait)

Tel. +965 482 9613, Fax +965 489 8035, E-Mail jpselvan58@yahoo.com 
Fig. 1. Pedigree. LDLC = Low-density lipoprotein cholesterol (mmol/l); HoZy = homozygous; IHD = ischemic heart disease; $\mathrm{XA}=$ xanthomas; $\mathrm{RCP}=$ recurrent chest pain; $\mathrm{APH}=$ apheresis; $\mathrm{N}=$ normal; $\mathrm{NK}=$ not known; arrow = index case.

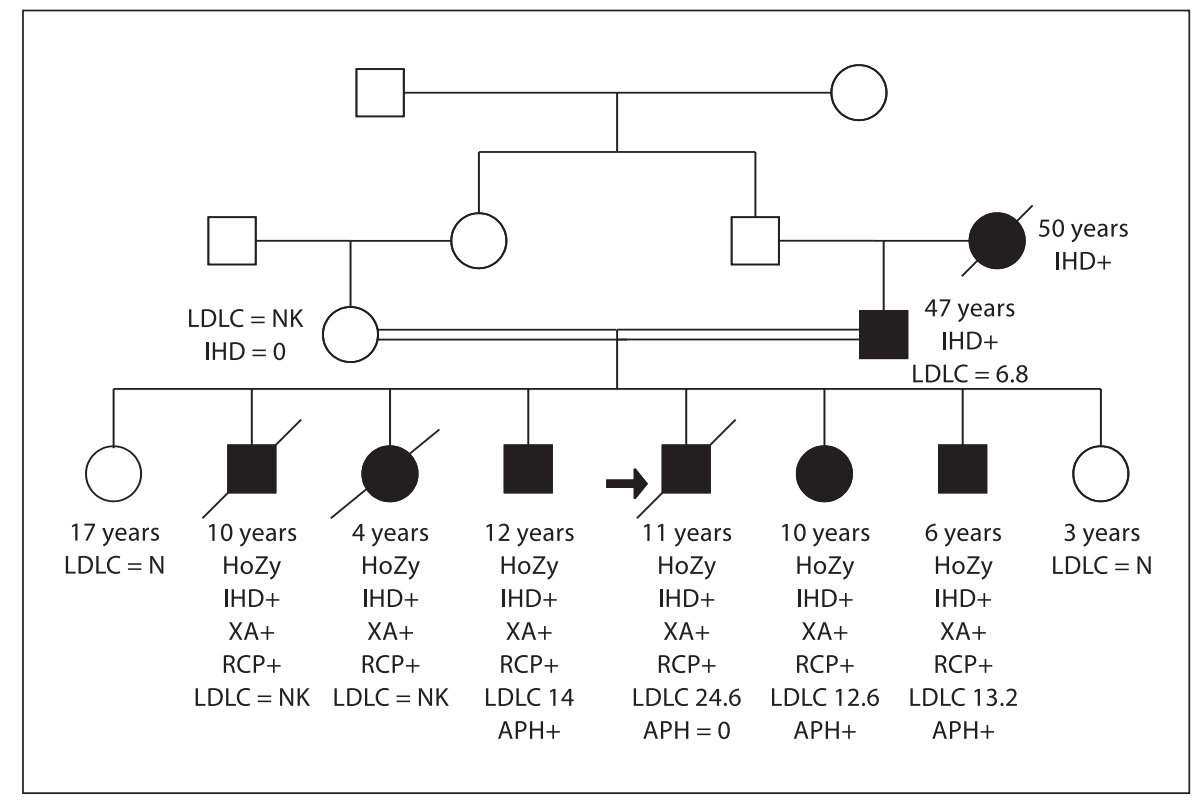

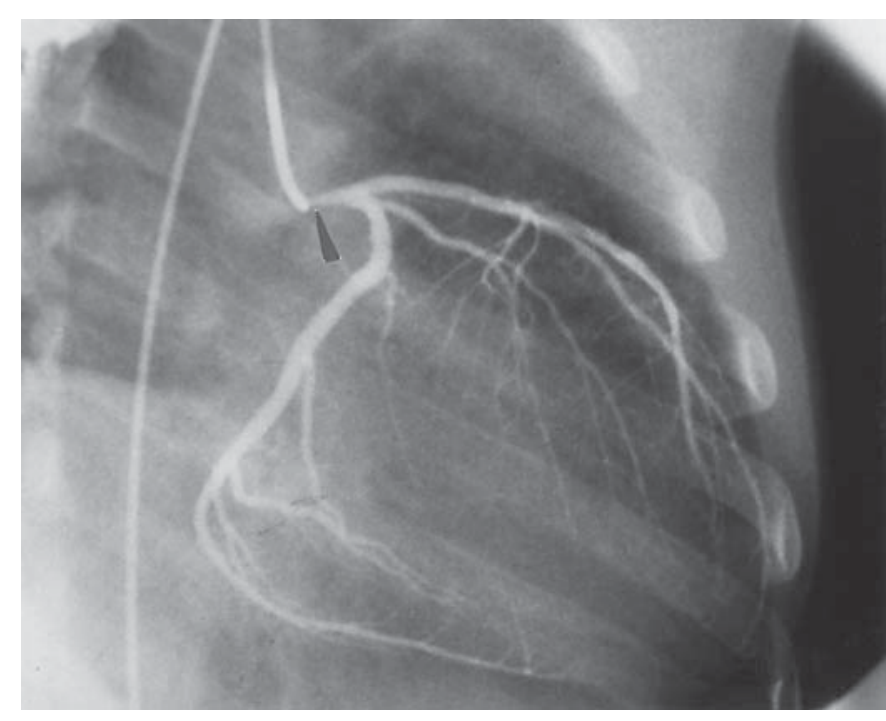

Fig. 2. Stenosis of the left main coronary artery.

and management of a boy with homozygous familial hypercholesterolemia (hoFH) who presented with multiple xanthomas and recurrent chest pain.

\section{Case Report}

An 11-year-old Kuwaiti boy presented with a history of recurrent episodes of chest pain. On examination he had planar xanthomas over the extensor surfaces of his wrists, ankles and dor- sum of his feet. Bilateral arcus cornealis was present. Blood pressure was 100/60 $\mathrm{mm} \mathrm{Hg}$. All pulses were palpable and there were no bruits heard over the major arteries. He had clinical features of moderate aortic stenosis and aortic regurgitation.

His family history was interesting and significant. His father and paternal grandmother were documented cases of hypercholesterolemia. The grandmother died at the age of 50 years after a myocardial infarction. Two of his siblings, a boy and a girl, died at 10 and 4 years of age, respectively, after recurrent chest pain and had multiple xanthomas. Three other siblings at 12,10 and 6 years of age have multiple xanthomas and are under treatment for established hypercholesterolemia, while 2 other siblings at 17 and 3 years of age are alive and normal. The pedigree is depicted in figure 1 with annotations of the known lipid investigations.

His resting electrocardiogram showed ST depression in the anterior and inferior leads. Two-dimensional and color Doppler echocardiography revealed thickened aortic valve with moderate regurgitation. The aortic valve was estimated to have a peak and mean gradient of 50 and $30 \mathrm{~mm} \mathrm{Hg}$, respectively, and the calculated valve area was $0.9 \mathrm{~cm}^{2} / \mathrm{m}^{2}$. Coronary angiogram outlined $70 \%$ stenosis of the left main coronary and ostial stenosis of the right coronary artery (fig. 2). There was extensive atherosclerotic disease of the aorta and all its major branches, i.e., arch vessels (fig. 3), renal (fig. 4), celiac and internal mammary arteries. The aorta itself showed narrowing just below the diaphragm and aneurismal changes at the lower part of the thoracic segment and just above the bifurcation of the abdominal segment (fig. 5). The lipid profile was grossly abnormal (total cholesterol $26.5 \mathrm{mmol} / \mathrm{l}$, LDL cholesterol $24.6 \mathrm{mmol} / \mathrm{l}$, triglyceride $2.5 \mathrm{mmol} / \mathrm{l}$ and HDL cholesterol $0.8 \mathrm{mmol} / \mathrm{l})$. The remaining biochemical and hematological parameters were normal. The patient was managed with metoprolol $12.5 \mathrm{mg}$ twice a day, nitroglycerin infusion, antithrombotics (aspirin $75 \mathrm{mg}$ once a day and heparin infusion 150 units/h), cholesterol-lowering drugs (simvastatin $10 \mathrm{mg}$ once a day, cholestyramine $4 \mathrm{~g}$ twice a day) and analgesics. It was planned 


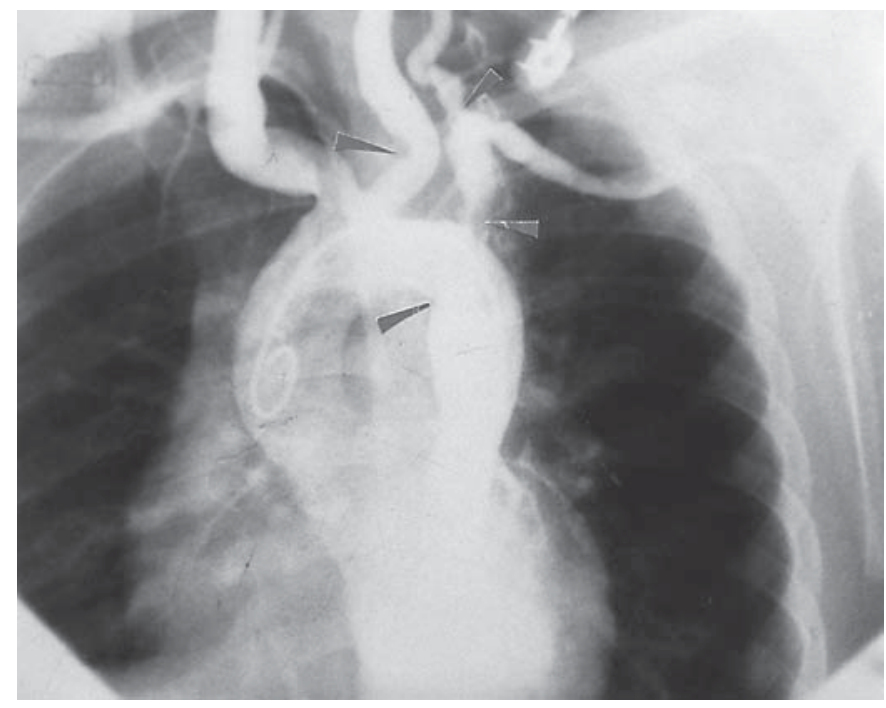

Fig. 3. Irregularities of the aortic arch and its branches.

to increase the simvastatin to a higher tolerated dose, and arrangements were being made to start him on plasmapheresis. The anginal episodes continued to worsen and on the fourth hospital day, he succumbed to severe coronary heart disease after an episode of ventricular tachyarrhythmia.

\section{Discussion}

Familial hypercholesterolemia is an autosomal dominant disorder with an incidence of 1 in 500 in most populations. From this, the incidence of homozygosity can be calculated to be 1 in a million $[1,2]$. The homozygous phenotype can usually be distinguished readily from the heterozygous phenotype [2]. Affected children almost always present before 5 years of age with arcus cornealis, planar and tendon xanthomas. The usual LDL cholesterol level at the time of diagnosis ranges from 12 to $24 \mathrm{mmol} / \mathrm{l}$ [2]. The high concentration of LDL cholesterol in plasma leads to accelerated atherosclerosis and extravascular lipid deposition in the homozygotes, leading to premature death following myocardial infarction in the first two decades of life [3]. It is imperative that complete cardiovascular assessment be done at the time of presentation so that the diagnosis can be made early. Earlier provision of effective treatment offers a better chance of modifying the course of this serious disorder [2].

Diet and pharmacological therapies are at best adjunctive to other therapeutic interventions. Diet therapy with restricted saturated fatty acids and cholesterol intake

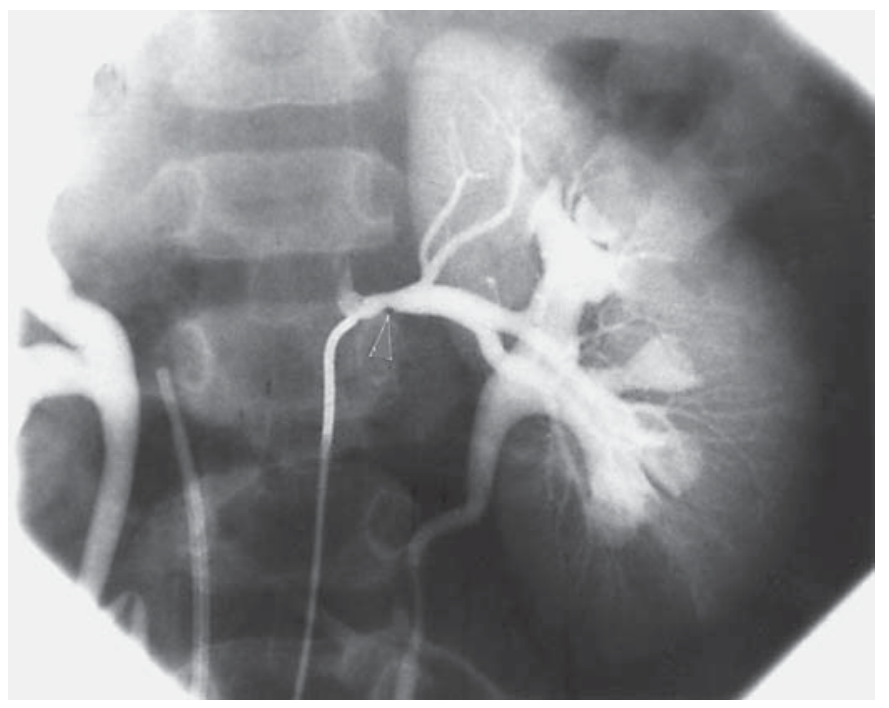

Fig. 4. Stenosis of the left renal artery.

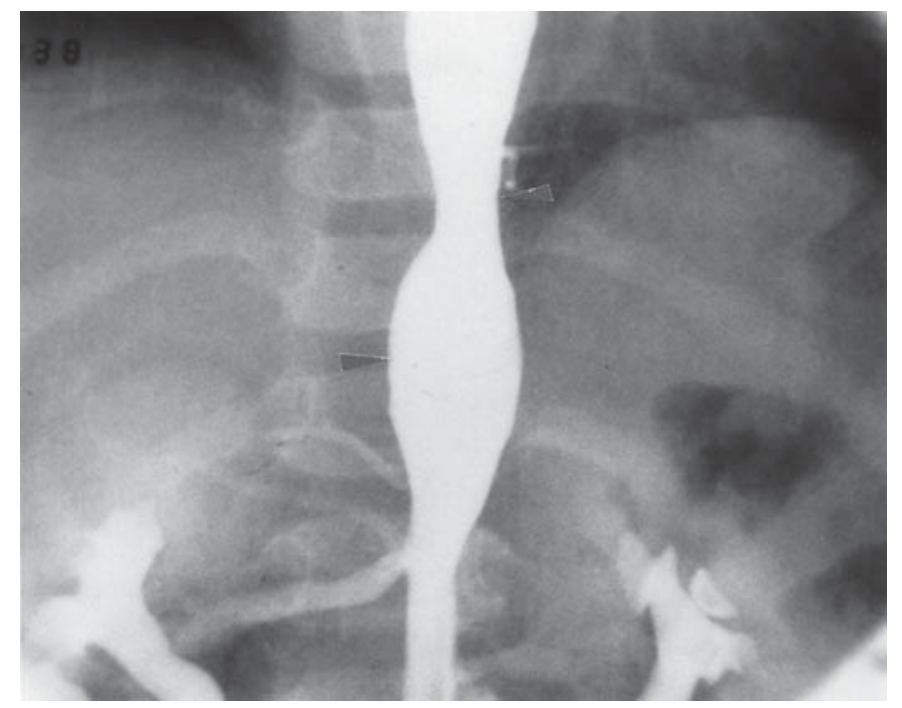

Fig. 5. Stenosis of the abdominal aorta with poststenotic dilatation.

achieves $10-15 \%$ reduction in LDL cholesterol [4]. Partial replacement of normal dietary fat consumption with sitostanol ester margarine appears to be safe and effective hypocholesterolemic treatment in children [5], but the power of reduction of LDL concentration is small and does not correct the biochemical derangement. Originally the Food and Drug Administration of the USA had approved only the use of bile acid sequestrants, i.e., chole- 
styramine and colestipol, in children $[1,4]$. Recent trials have demonstrated the safety and efficacy of long-term use of HMG-COA reductase inhibitors in children [2, 6]. Single or combination drug therapies in children reduce LDL cholesterol only by 30-40\% [4]. In hoFH, drug therapy is even less effective, since the effects of the majority of cholesterol-lowering medications are mediated by upregulation of LDL receptors, which are often not present or poorly functional in homozygous patients. Probucol has been used in homozygous patients, and in addition to its potent antioxidant properties, it has been shown to reduce levels of LDL cholesterol by about a quarter with important regression of xanthomas [2]. Despite the additional success of probucol as an adjunct to statins in hoFH [2], more intensive forms of intervention are required to achieve ideal LDL levels.

Other modalities like ileal bypass surgery, portocaval shunt and biliary diversion have been tried. Although liver transplant was effective, it could not be established as a safe form of therapy in children with hoFH [7]. LDL apheresis represents a useful nonpharmacological tool to treat severe hypercholesterolemia. A mean reduction in plasma levels of total cholesterol and LDL cholesterol by $60-85 \%$ has been demonstrated $[8,9]$. An average plasma concentration of LDL cholesterol lower than $5.4 \mathrm{mmol} / \mathrm{l}$ can be achieved by treating patients once a week [9]. Along with the improvement of the plasma atherogenic profile, regression of cutaneous xanthomas and preven- tion of progression of coronary heart disease have been shown to avert early death $[2,10]$. A combination of apheresis and statins was found to improve LDL reduction in subjects who had absent or minimal receptor activity [2]. Although it is not curative, owing to its simplicity, selectivity and safety, apheresis using dextran sulfate cellulose column is possibly the optimum means currently available for extracorporeal removal of LDL cholesterol [11]. Direct adsorption of LDL from blood has recently been shown to be effective as well.

An ex vivo approach to gene therapy for hoFH has been developed in which the recipient is transplanted with autologous hepatocytes that are genetically corrected with recombinant retrovirus carrying the LDL receptor. In vivo LDL catabolism was increased by $53 \%$ following gene therapy in receptor-negative patients [12]. This form of treatment holds promise for a selected few with hoFH only if it can provide sustained expression of LDL receptors.

\section{Conclusion}

This case report emphasizes the need to diagnose familial hypercholesterolemia in families with premature heart disease and the need to test partners of affected persons so that the risk of conceiving children with hoFH can be counseled.

\section{References}

1 Barbagallo CM, Averna MR, DiMarco T, Spano L, Scafidi V, Marino G, Camemi AR, Notarbartello A: Effectiveness of cascade filtration plasmapheresis in two patients affected by familial hypercholesterolemia. J Clin Apheresis 1995;10:96-100.

-2 Shaikh AM, Abdullah MH, Barclay A, Cullen-Dean G, McCrindle BW: Impact of the characteristics of patients and their clinical management on outcomes in children with homozygous familial hypercholesterolemia. Cardiol Young 2002;12:105-112.

>3 Ducobu J, Brasseur D, Chaudron JM, Deslypere JP, Harveng TC, Muls E, Thomson M: Simvastatin use in children. Lancet 1992; 339:1488.

4 Grossman M, Rader DJ, Muller DW, Kolansky DM, Kozarsky K, Clark BJ, Stei EA, Lupien PJ, Brewer HB, Raper SE, et al: A pilot study of ex vivo gene therapy for homozygous familial hypercholesterolaemia. Nat Ed 1995;1:1148-1154.
5 Gylling H, Siimes MA, Miettinen TA: Sitostanol ester margarine in dietary treatment of children with familial hypercholesterolemia. J Lipid Res 1995;36:1807-1812.

6 Lasuncion MA, Tervel JL, Alvarez JJ, Carrero P, Ortuno J, Gomez-Coronado D: Changes in lipoprotein, LDL-cholesterol and apolipoprotein $\mathrm{B}$ in homozygous familial hypercholesterolemic patients treated with dextran sulfate LDL apheresis. Eur J Clin Invest $1993 ; 23: 819-826$.

7 National Cholesterol Education Program: Report of the Expert Panel on Blood Cholesterol Levels in Children and Adolescents. Pediatrics 1992;89(suppl):515-584.

8 Park MK: Pediatric Cardiology for Practitioners, ed 3. St Louis, Mosby, 1996, pp 434442 .
-9 Raper SE, Grossman M, Rader DJ, Thoene JG, Clark BJ, Kolansky DM, Muller DW, Wilson JM: Safety and feasibility of liver-directed ex vivo gene therapy for homozygous familial hypercholesterolemia. Ann Surg 1996; 223:116-126

10 Revell SP, Noble-Jamieson G, Johnston P, Rasmussen A, Jamieson N, Barnes ND: Liver transplantation for homozygous familial hypercholesterolemia. Arch Dis Child 1995;73: 456-458.

11 Tershakovec AM, Coates PM, Cortner JA: Disorders of lipoprotein metabolism and transport; in Nelson WE, Behrman RE, Kliegman RM, Arvin AM (eds): Nelson Textbook of Pediatrics. London, Saunders, 1996, pp 381-382.

12 Uauy R, Zwiener RJ, Phillips MJ, Petruska ML, Bilheimer DW: Treatment of children with homozygous familial hypercholesterolemia. J Pediatr 1992;120:892-898. 